\title{
Production of platelet-activating factor by the pre-implantation sheep embryo
}

\author{
K. M. Battye ${ }^{1}$, A. J. Ammit ${ }^{1}$, C. O’Neill ${ }^{1}$ and G. Evans ${ }^{2}$
}

${ }^{1}$ Human Reproduction Unit, Royal North Shore Hospital, St Leonards, NSW 2065, Australia; and ${ }^{2}$ Department of Animal Science, University of Sydney, Sydney, NSW 2006, Australia

\begin{abstract}
Summary. Embryos were collected from superovulated ewes on Day 2 (2-8 cell), Day 4 (8-16 cell) and Day 6 (morula/early blastocyst). Two embryos were cultured in $1 \mathrm{ml}$ of one of four media: (i) Ham's F10 $+4 \mathrm{mg}$ bovine serum albumin (BSA)/ml, (ii) synthetic oviduct fluid medium $+20 \%$ human serum, (iii) Quinn's human tubal fluid medium (HTF) $+3 \mathrm{mg} \mathrm{BSA} / \mathrm{ml}$ or (iv) $\mathrm{HTF}+10 \%$ acid-treated fetal calf serum for $24 \mathrm{~h}$. They were transferred to fresh media of the same type and their further development was monitored. A quantitative bioassay and radioimmunoassay was used to measure the concentration of platelet-activating factor (PAF, 1-o-alkyl-2-acetyl-snglyceryl-3-phosphocholine) produced. Following extraction and partial purification, $21 / 95(22 \cdot 1 \%)$ of the embryo-conditioned media samples had PAF concentrations greater than that measured in corresponding control media. This was designated as embryo-derived PAF and the corresponding cultures were termed 'PAF-positive'. PAF was produced by embryos at all three developmental stages examined and in each of the four media used, and the average amount of PAF produced was $60.9 \pm 9.8 \mathrm{pmol} /$ embryo $/ 24 \mathrm{~h}$. However, neither the developmental stage of the embryo, nor the type of media affected the proportion of PAF-positive cultures nor the amount of PAF produced during culture. Thus, it is demonstrated for the first time that early ovine embryos can secrete PAF in vitro, and that there is considerable variability in their capacity for PAF secretion.
\end{abstract}

Keywords: platelet-activating factor; embryo; in vitro; sheep

\section{Introduction}

Pre-implantation mice (O'Neill, 1985; Collier et al., 1988; Ryan et al., 1989) and human (Collier et al., 1988, 1990) embryos secrete an ether phospholipid which is homologous with plateletactivating factor (PAF, 1-o-alkyl-2-acetyl-sn-glyceryl-3-phosphocholine). The amount of PAF produced by human embryos was positively correlated with their pregnancy potential after transfer (O'Neill, 1987). Embryo-derived PAF appears to have an autocrine role, since (i) there is a direct, specific influence of exogenous PAF in vitro on the oxidative metabolism of energy substrates (glucose and lactate) by mouse embryos (Ryan et al., 1989, 1990a), (ii) supplementation of culture media with PAF in which 2-cell mouse embryos were cultured for $72 \mathrm{~h}$ increased the number of cells in the expanded blastocysts, (iii) similar supplementation of media significantly increased the implantation rate and pregnancy potential of both mouse (Ryan et al., 1990b) and human (O'Neill et al., 1989) embryos and (iv) treatment of mouse embryos with PAF inhibitors prevented blastocyst outgrowth in vitro (Spinks et al., 1990) and the ability of embryos to implant in vivo (Spinks \& O'Neill, 1988; Spinks et al., 1990). PAF may also exert effects on maternal physiology as evidenced by mild, but significant, thrombocytopenia in some species (mouse, O'Neill, 1985; cow, Hansel, 1988), the attenuation of oxytocin-induced prostaglandin (PG) F-2 $\alpha$ release from the ovine 
uterus in vivo (Battye et al., 1989), and the modification of prostaglandin secretion by human (Smith \& Kelly, 1988) and bovine (Gross et al., 1990) endometrium in vitro.

To date, the production of PAF by the ovine embryo has not been investigated. This experiment was conducted to determine whether PAF is secreted at various developmental stages by sheep embryos.

\section{Materials and Methods}

Superovulation. Thirty Merino ewes (6 years old) underwent superovulation and embryo recovery twice, with a 6week interval between surgical embryo collection. The oestrous cycle was synchronized by treatment with intravaginal sponges (60 mg medroxyprogesterone; Repromap, Upjohn, Sydney, NSW, Australia) for 12-13 days. The ewes were superovulated by an intramuscular injection of 1200 iu pregnant mares' serum gonadotrophin (PMSG; Folligon: Intervet, Boxmeer, Netherlands) 2 days before sponge removal. Oestrus was detected using harnessed entire rams. Laparoscopic insemination was conducted $48-52 \mathrm{~h}$ after sponge removal. The ewes were inseminated with fresh semen, diluted 1:2 with Dulbecco's phosphate-buffered saline (PBS) with antibiotics.

Embryo recovery. Embryos were recovered by midventral laparotomy as described by Moore (1980) on Days 2, 4 and 6 after oestrus. Embryo collections were conducted under general anaesthesia ( $60 \mathrm{mg}$ sodium pentobarbitone/ml: Cava Chemicals, NSW). Embryos were flushed from the uterus in PBS supplemented with $5 \%$ heat-inactivated fetal calf serum (FCS). Embryos were rinsed twice in PBS + 20\% FCS, transferred to sterile $5 \mathrm{ml}$ tubes (Flow Laboratories, Sydney, NSW, Australia) containing $1 \mathrm{ml}$ of PBS $+20 \%$ FCS. Embryos were held in the incubator at $30^{\circ} \mathrm{C}$ until surgery was completed and then transferred to the culture laboratory.

Embryo culture. Since optimal culture conditions for ovine embryos are not well defined, embryos were cultured in either (i) Ham's F10 (Flow Laboratories) supplemented with $4 \mathrm{mg}$ bovine serum albumin/ml (BSA, Pentex, Miles, Inc., Karakee, IL, USA; w/v), (Ham's + BSA), (ii) synthetic oviduct fluid medium (Walker et al., 1988) supplemented with $20 \%(\mathrm{v} / \mathrm{v})$ heat-inactivated human serum (HS) (SOFM + HS), (iii) Quinn's human tubal fluid medium (HTF; Quinn et al., 1985) supplemented with $3 \mathrm{mg}$ BSA/ml (w/v), (HTF + BSA) or (iv) HTF supplemented with $10 \%$ (v/v) acid-treated FCS (O'Neill et al., 1989) (HTF + FCS). Acidified FCS was used as a protein source, as acidification destroys PAF:acetylhydrolase activity (Blank et al., 1983), an enzyme that deactivates PAF. Where possible, embryos from each sheep were allocated across the four media treatments. Embryos were rinsed twice in the specified medium before transfer to the culture tube. Generally, two embryos were cultured in $1 \mathrm{ml}$ of media in sterile plastic tubes (Flow Laboratories) in $5 \% \mathrm{CO}_{2}$ in air at $37^{\circ} \mathrm{C}$. After $24 \mathrm{~h}$, embryos were removed from the culture tube, assessed for development, transferred to a $10 \mu \mathrm{l}$ drop of the same medium under oil and placed back into culture. Culture was continued in $5 \% \mathrm{CO}_{2}$ in air at $37^{\circ} \mathrm{C}$ for another 144,96 or $48 \mathrm{~h}$ for embryos collected on Days 2,4 and 6 , respectively. The culture tubes were gassed with $5 \% \mathrm{CO}_{2}$ in air and stored at $-20^{\circ} \mathrm{C}$ until extraction.

Extraction of embryo-derived PAF from culture media. Embryo-derived PAF was extracted from the $24 \mathrm{~h}$ culture media using the method described by Collier $e t$ al. (1988). All solvents used were high-performance liquid chromatography grade (BDH, Poole, UK). The culture medium (1 volume) was deproteinized by dropwise addition to 19 volumes of methanol. After $30 \mathrm{~min}$ of incubation at room temperature, the protein precipitate was removed by centrifugation $\left(2500 \mathrm{~g}\right.$ for $20 \mathrm{~min}$ at $4^{\circ} \mathrm{C}$ ). The supernatant was passed through a Sep-pak $\mathrm{C} 18$ cartridge (Millipore, Milford, MA, USA) to remove nonpolar lipids, and to 1 volume of eluate 0.8 volumes of water and 0.95 volumes of chloroform were added to effect phase separation. The chloroform phase was reduced to $0.5-1.0 \mathrm{ml}$ in a rotary evaporator and further concentrated to $200 \mu \mathrm{l}$ under a stream of $\mathrm{N}_{2}$. This concentrate was applied to a $0.25 \mathrm{~mm}$ silica gel thin-layer chromatography (TLC) plate (Merck, Darmstadt, Germany) and developed in chloroform:methanol:water $(65: 35: 6, \mathrm{v} / \mathrm{v})$. The migration of synthetic PAF $(5 \mu \mathrm{g})$, run as a reference, was visualized with Phospray (Supelco, Bellefonte, PA, USA).

Embryo-derived PAF was removed from the TLC plate by scraping the area corresponding to the $R_{\mathrm{f}}$ of synthetic $\operatorname{PAF}\left(R_{\mathrm{f}}=0 \cdot 22 \pm 0 \cdot 01, n=32\right)$ and eluted with $2 \mathrm{ml}$ of chloroform:methanol:water $(1: 2: 0 \cdot 8, \mathrm{v} / \mathrm{v})$. Following centrifugation $(1500 \mathrm{~g}$ for $10 \mathrm{~min})$, the solvent was removed to a clean tube. Chloroform $(0.5 \mathrm{ml})$ and water $(0.5 \mathrm{ml})$ were added to effect phase separation. The lower chloroform phase was washed once with $1 \mathrm{ml}$ of methanol:water (10:9, $\mathrm{v} / \mathrm{v}$ ). The lower phase was removed to a clean tube and evaporated to dryness under $\mathrm{N}_{2}$. The residue was resuspended in $250 \mu \mathrm{l}$ in PBS free of $\mathrm{Ca}^{2+}$ and $\mathrm{Mg}^{2+}+2.5 \mathrm{mg} \mathrm{BSA} / \mathrm{ml}$ (w/v) (CSL, Melbourne, Vict, Australia), for quantification in the bioassay.

The efficiency of PAF extraction was followed by monitoring the recovery of $\left[{ }^{3} \mathrm{H}\right] \mathrm{PAF}$ (NET-668 200000 c.p.m., $56.7 \mathrm{Ci} / \mathrm{mmol}$, NEN Du Pont) added to the culture media prior to extraction. The recovery of [ $\left.{ }^{3} \mathrm{H}\right] \mathrm{PAF}$ was used to correct for losses of embryo-derived PAF during extraction by multiplying the observed activity in the PAF assays by the reciprocal of the $\left[{ }^{3} \mathrm{H}\right] \mathrm{PAF}$ recovery.

For all extractions of embryo culture medium, a control blank was also extracted. The control blank was the same medium, but had not been exposed to embryos. The PAF concentrations measured in the control blanks were subtracted from the unknown sample PAF determinations after both had been corrected for $\left[{ }^{3} \mathrm{H}\right] \mathrm{PAF}$ recovery. 
PAF bioassay. The embryo-derived PAF was measured using a sensitive rabbit platelet bioassay (Collier et al., 1988). The concentration of PAF was related directly to the degree of platelet aggregation induced in a sample of whole blood in the presence of citrate anticoagulant, an ADP scavenger (phospho(enol) pyruvate and pyruvate kinase), and the cyclo-oxygenase inhibitor acetylsalicylic acid (all Sigma Chemical Co., St Louis, MO, USA). The number of single nonaggregated platelets was counted on a Baker Series 810 platelet analyser (Baker Instruments, Pennsylvania, USA). Each positive sample was tested with the PAF-specific receptor antagonist SRI 63-441 (Sandoz, NJ, USA) (Handley et al., 1986) to confirm that the platelet aggregation induced by embryo culture media extract was due to PAF. The detection limit of the bioassay was $5.6 \mathrm{nM}(3 \mathrm{ng} / \mathrm{ml})$ (Collier et al., 1990).

A culture was defined as PAF positive if the PAF concentration was greater than the mean +1.96 standard deviations of the specific control blanks.

Comparison of $P A F$ bioassay and $P A F$-specific radioimmunoassay. There was insufficient sample left after bioassay to test each sample individually with the radioimmunoassay (RIA). Therefore, samples of embryo-derived PAF in PBS-BSA which showed similar concentration in the bioassay were pooled. Very low (below the sensitivity of the bioassay), low (11-37 nM), medium (43-112 nM) and high (141-366 nM) extracted samples of embryo-derived PAF were pooled and assayed using a radioimmunoassay for PAF (NEN Du Pont, NEK-062). The PAF-RIA was performed according to the manufacturer's instructions. The PAF-RIA kit uses PAF-specific antibodies raised in sheep. The labelled PAF-antibody complex was precipitated by a second antibody and the radioactivity in the precipitate was measured. The amount of labelled PAF in the precipitate is inversely proportional to the amount of PAF in the solution being assayed. The sheep anti-PAF antibody used in the RIA is highly specific for PAF (Smal et al., 1990). The sensitivity of the RIA was $0.56 \mathrm{~nm}(0.30 \mathrm{ng} / \mathrm{ml})$ and the interassay coefficient of variation was $5.3 \%$.

As the PAF-RIA was not commercially available until towards the completion of this study, all samples were initially measured using the quantitative bioassay. Therefore, the concentrations of PAF reported in the Results are derived from the bioassay.

Enzymatic analysis. Analysis of embryo-derived PAF was performed using phospholipase $\mathrm{A}_{2}$ (PLA $)$ (EC 3.1.1.4, bee venom, Sigma, USA). The enzyme was dissolved in Tris-buffered saline, $\mathrm{pH} 8$, at $\mathrm{I} 80 \mathrm{iu} / \mathrm{ml}$ and dilutions in the same buffer were made from a stock solution. Samples of synthetic PAF or embryo-derived PAF ( $75 \mu \mathrm{l})$ with the same bioactivity, were incubated with PBS-BSA or various concentrations of PLA $\mathrm{A}_{2}$ in $15 \mu \mathrm{l}$ of buffer for $15 \mathrm{~min}$ at $37^{\circ} \mathrm{C}$. Samples $(50 \mu \mathrm{l})$ were added to $50 \mu \mathrm{l}$ of rabbit blood in the standard bioassay.

Statistical analysis. Embryo development and the proportion of PAF-positive cultures were analysed by logistic regression. The concentration of PAF produced by cultures was analysed by one-way analysis of variance with respect to media treatment and developmental stage of the embryo. The concentration of PAF in control culture medium was analysed by one-way analysis of variance. Differences between means were compared using Duncan's multiple range test (Steel \& Torrie, 1981). Data are presented as mean \pm s.e.m.

\section{Results}

\section{Embryo development}

When embryos were recovered on Day 6 (morula/early blastocyst), the proportion developing through to expanded/hatching blastocyst by Day 8 (after $48 \mathrm{~h}$ in culture) was significantly higher $(P<0.001)$ than when embryos were recovered on Day $2(2-8$ cell) and cultured for 144 h or Day 4 (8-16 cell) and cultured for $96 \mathrm{~h}$ (Table 1). SOFM + HS was the only medium in which 2-8 cell embryos (recovered on Day 2) developed to the expanded/hatching blastocyst stage by Day 8. Over the three developmental stages examined, more embryos cultured in Ham's + BSA or SOFM + HS tended to develop to expanded/hatching blastocyst $(P=0.07)$ than embryos cultured in HTF + BSA or HTF + FCS.

\section{PAF concentration in culture media}

Low concentrations of PAF were measured consistently in culture media not exposed to embryos (control blanks), and were higher in SOFM + HS than in the three other media $(P<0.01$, Table 2$)$. The PAF activity was inhibited when tested in the presence of the PAFreceptor antagonist, SRI 63-441, suggesting that it was PAF, but not PAF derived from embryos.

There was wide variation in the concentration of PAF measured in culture medium in which sheep embryos had been grown for $24 \mathrm{~h}(0-411 \mathrm{~nm}$, i.e. 0-205 pmol/embryo/24 h). Overall, 21/95 $(22.1 \%)$ cultures were PAF-positive (Table 3 ). There was no significant effect of culture medium used, or the developmental stage of the embryo, on the proportion of cultures that were positive for 
Table 1. Proportion of ovine embryos which developed to expanded blastocysts or further by Day 8; percentages in parentheses

\begin{tabular}{llccc}
\hline & \multicolumn{5}{c}{ Developmental stage of embryos at collection } \\
\cline { 2 - 6 } $\begin{array}{l}\text { Time in } \\
\text { culture (h) }\end{array}$ & $\begin{array}{c}\text { Day } 2 \\
144\end{array}$ & $\begin{array}{c}\text { Day } 4 \\
96\end{array}$ & $\begin{array}{c}\text { Day } 6 \\
48\end{array}$ & Total \\
\hline Media* $_{\text {Ham's + BSA }}$ & $0 / 4$ & $1 / 4(25 \cdot 0)$ & $25 / 31(80 \cdot 6)$ & $26 / 39(66 \cdot 7)$ \\
SOFM + HS & $5 / 11(45 \cdot 5)$ & $3 / 6(50 \cdot 0)$ & $25 / 31(80 \cdot 6)$ & $33 / 48(68 \cdot 8)$ \\
HTF + BSA & $0 / 4$ & $0 / 5$ & $22 / 31 \quad(71 \cdot 0)$ & $22 / 40(55 \cdot 0)$ \\
HTF + FCS & $0 / 10$ & $1 / 6(16 \cdot 7)$ & $26 / 33(78 \cdot 8)$ & $27 / 49(55 \cdot 1)$ \\
& $5 / 29(17 \cdot 2)^{\mathrm{b}}$ & $5 / 21(23 \cdot 8)^{\mathrm{b}}$ & $98 / 126(77 \cdot 8)^{\mathrm{a}}$ & $108 / 176(61 \cdot 4)$ \\
\hline
\end{tabular}

*BSA, bovine serum albumin; SOFM, synthetic oviduct fluid medium; HS, human serum; HTF, human tubal fluid medium; FCS, fetal calf serum.

Values with different superscripts are significantly different at $(P<0.05)$.

Table 2. Concentration of plateletactivating factor (PAF, $\mathrm{nmol} / \mathrm{l})$ in culture medium not exposed to ovine embryos, measured using the quantitative bioassay after extraction of culture media and partial purification by thin-layer chromatography

\begin{tabular}{lcc}
\hline Media* $^{*}$ & $n$ & $\begin{array}{c}\text { PAF (nmol/l) } \\
\text { mean } \pm \text { s.e.m. }\end{array}$ \\
\hline Ham's + BSA & 16 & $18 \cdot 28 \pm 2 \cdot 09^{\mathrm{b}}$ \\
SOFM + HS & 13 & $32.42 \pm 3.86^{\mathrm{a}}$ \\
HTF + BSA & 20 & $19 \cdot 03 \pm 2.32^{\mathrm{b}}$ \\
HTF + FCS & 20 & $19.68 \pm 1.71^{\mathrm{b}}$ \\
\hline
\end{tabular}

*See Table 1 for key to abbreviations.

Values with different superscripts are significantly different at $P<0.05$.

PAF. The media $\times$ day interaction was significant $(P=0.03)$ and may be explained by the observation that PAF-positive cultures were detected in Ham's + BSA and SOFM + HS across the 3 embryo collection days, but not in HTF + BSA Day 2 or Day 4 cultures, and HTF + FCS Day 2 and Day 6 culture media.

PAF was produced by embryos in the four media tested, the amount of PAF secreted by embryos not differing between media $(P>0.05)$, although there was a trend towards higher amounts being produced in SOFM + HS when PAF-positive cultures only were considered (Table 4). The amount of PAF produced by embryos was not affected by the stage of development (Table 4). Therefore, when the data were pooled, the average amount of PAF produced by embryos in the PAF-positive cultures was $60.9 \pm 9 \cdot 8 \mathrm{pmol} / \mathrm{embryo} / 24 \mathrm{~h}$.

Overall, 19/23 (82.6\%) of the embryos in Day 6 PAF-positive cultures developed during culture, so that in all of these cultures at least one of the two embryos had cleaved. Of the Day 2 and Day 4 PAF-positive cultures, 14/18 (77.8\%) embryos went through one mitotic division in the first $24 \mathrm{~h}$ in culture. There was one Day $2 \mathrm{PAF}$-positive culture in which the embryos did not develop. In the 'PAF-negative' cultures, 67/80 (83.8\%) Day 6 embryos developed, and 43/60 (71.7\%) Day 2 and Day 4 embryos went through at least one mitotic division in the first $24 \mathrm{~h}$ period. 
Table 3. Proportion of ovine embryo cultures where the concentration of platelet-activating factor was greater than the mean $\pm 1.96 \mathrm{~s}$.d. of that measured in culture media not exposed to embryos; percentages in parentheses

\begin{tabular}{llccc}
\hline & \multicolumn{4}{c}{ Developmental stage of embryos at collection } \\
\cline { 2 - 5 } Media* & \multicolumn{1}{c}{ Day 2} & Day 4 & Day 6 & Total \\
\hline Ham's + BSA & $1 / 5(20)$ & $2 / 6(33)$ & $5 / 16(31)$ & $8 / 27(30)$ \\
SOFM \pm HS & $2 / 4(50)$ & $2 / 7(29)$ & $2 / 10(20)$ & $6 / 21(29)$ \\
HTF + BSA & $0 / 5$ & $0 / 5$ & $5 / 14(36)$ & $5 / 24(21)$ \\
HTF + FCS & $0 / 5$ & $2 / 5(40)$ & $0 / 13$ & $2 / 23(9)$ \\
& $3 / 19(16)$ & $6 / 23(26)$ & $12 / 53(23)$ & $21 / 95(22)$ \\
\hline
\end{tabular}

*See Table 1 for key to abbreviations.

Table 4. Concentration of platelet-activating factor (PAF, nmol/l) in PAFpositive cultures, measured using the quantitative bioassay after extraction of culture media and partial purification by thin-layer chromatography

\begin{tabular}{|c|c|c|c|c|}
\hline \multirow[b]{2}{*}{ Media* } & \multicolumn{4}{|c|}{ Developmental stage of ovine embryos at collection } \\
\hline & Day 2 & Day 4 & Day 6 & Mean \\
\hline $\begin{array}{l}\text { Ham's + BSA } \\
\text { SOFM + HS } \\
\text { HTF + BSA } \\
\text { HTF + FCS }\end{array}$ & $\begin{array}{c}37 \cdot 0 \\
155 \cdot 4 \\
- \\
-\end{array}$ & $\begin{array}{c}42 \cdot 0 \\
265 \cdot 5 \\
- \\
73 \cdot 6\end{array}$ & $\begin{array}{c}164.2 \pm 27 \cdot 9 \\
131.0 \\
70.6 \pm 9.9 \\
-\end{array}$ & $\begin{array}{c}117 \cdot 7 \pm 28 \cdot 2 \\
184 \cdot 0 \pm 48 \cdot 7 \\
70 \cdot 6 \pm 9 \cdot 9 \\
73.6\end{array}$ \\
\hline & $115.9 \pm 45.9$ & $127 \cdot 0 \pm 45 \cdot 5$ & $119 \cdot 7 \pm 18 \cdot 4$ & $121 \cdot 2 \pm 19 \cdot 5$ \\
\hline
\end{tabular}

*See Table 1 for key to abbreviations.

\section{Comparison of bioassay and radioimmunoassay}

Pooled samples of embryo-derived PAF (previously bioassayed) were measured by the PAF-RIA. There was agreement between the two assay systems in ranking of concentrations of the samples, i.e. low, medium and high, the RIA having greater sensitivity than the bioassay and giving 1.5-3.5 times higher values. Because of the limited amount of material available for this retrospective analysis, a direct comparison of the bioassay and the RIA was not possible.

\section{Structural study}

The acetyl group from the $C_{2}$ position is essential for biological activity of PAF, and is removed by PLA $_{2}$ (Benveniste et al., 1977). Pretreatment of synthetic and embryo-derived PAF (41 nM) with $30 \mathrm{iu} / \mathrm{ml} \mathrm{PLA}_{2}$ (measured in duplicate), reduced the platelet-aggregating activity of both to a similar extent (Fig. 1). Only single measurements were made at PLA 2 concentrations of $7 \cdot 5$ and $15 \mathrm{iu} / \mathrm{ml}$, because of a lack of sample, but, at each of these concentrations, the bioactivities of synthetic PAF and embryo-derived PAF were similar.

\section{Discussion}

This is the first report showing that some early pre-implantation sheep embryos secrete the ether phospholipid, PAF, in culture. Biologically active, sheep embryo-derived PAF co-migrated with 


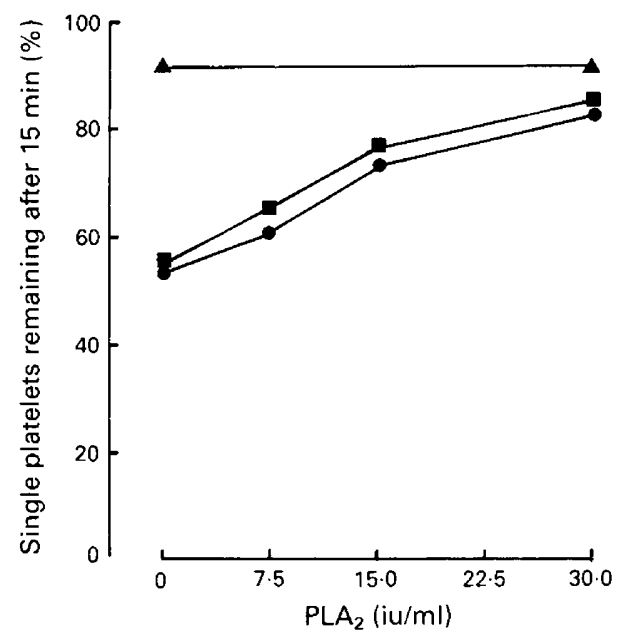

Fig. 1. Deactivation of platelet-activating factor (PAF) by phospholipase $A_{2}\left(P_{2 A}\right)$. Samples of phosphate-buffered saline and bovine serum albumin $(\boldsymbol{A})$, synthetic PAF $(\boldsymbol{O})$ or ovine embryo-derived PAF ( $\mathbf{\square}$ ) of equivalent activity to $41 \mathrm{nmol} / 1$ were pre-incubated for $15 \mathrm{~min}$ at $37^{\circ} \mathrm{C}$ with $7 \cdot 5,15$ or 30 iu PLA $/ \mathrm{ml}$ prior to bioassay. A $50 \mu \mathrm{l}$ sample was then added to $50 \mu \mathrm{l}$ of rabbit blood and the number of single platelets remaining after $15 \mathrm{~min}$ was expressed as a percentage of those present initially. Data points at 0 and $30 \mathrm{iu} / \mathrm{ml}$ are the mean of two determinations, the remainder are single determinations because of a lack of embryo-derived PAF.

both synthetic PAF and $\left[{ }^{3} \mathrm{H}\right] \mathrm{PAF}$ on silica TLC. While this study was being conducted, a radioimmunoassay for PAF (NEN Du Pont, NEK-062) became available for the quantitative detection of PAF. The RIA was more sensitive than the bioassay (Ammit \& O'Neill, 1991) while both methods for measuring PAF ranked samples in the same way. Substantial support exists for the specificity of the antisera for 1-o-alkyl-2-acetyl-sn-glyceryl-3-phosphocholine (Smal et al., 1989, 1990; Cooney et al., 1990). The detection of putative embryo-derived PAF by the radioimmunoassay offers further support for structural homology between ovine embryo-derived PAF and 1-o-alkyl-2-acetyl-sn-glyceryl-3-phosphocholine. The deactivation of sheep embryo-derived PAF by $\mathrm{PLA}_{2}$ confirms that the PAF produced by sheep embryos is homologous with that produced by mouse and human embryos (Collier et al., 1988).

PAF was produced by sheep embryos at the three developmental stages examined (2-8 cell, $8-16$ cell, morula/early blastocyst) (Tables 3 and 4). PAF production by mouse embryos at these stages has been reported (Collier et al., 1988; Ryan, 1989), and by human embryos at the 1-4 cell stage (Collier et al., 1988, 1990). In this study, no difference was observed between the three developmental stages on the proportion of cultures which were PAF-positive. However, the numbers of positive cultures on Days 2 and 4 were low.

It has been suggested that PAF production by embryos may serve as a marker for embryo viability and pregnancy potential (O'Neill, 1987). Collier et al. (1990) showed that, while there was a significant correlation between PAF production by human embryos and pregnancy potential, it was not an absolute marker since $13 \%$ of patients who became pregnant received embryos which did not produce PAF in vitro. In this study it has been shown that, for the sheep embryo, there was no correlation between the secretion of PAF and their development in vitro. Since embryo transfers were not performed, it is not possible to determine if it was a marker of pregnancy potential, as in the human.

Collier et al. (1988) reported the measurement of nonspecific PAF activity in protein-free media, media supplemented with $3 \mathrm{mg} / \mathrm{ml}$ BSA and HTF plus $10 \%$ maternal human serum (Collier et al., 1990). PAF activity was measured consistently in control media blanks in this study, but was 
highest in SOFM + HS. The apparent low 'PAF-like' activity was observed in both the bioassay and RIA. The extraction procedure and/or addition of $\left[{ }^{3} \mathrm{H}\right] \mathrm{PAF}$ to culture media may have contributed to the low levels measured. The presence of PAF in human and rat serum has been reported (Caramelo et al., 1984); this may explain the significantly higher concentrations detected in SOFM + HS. However, similar concentrations of PAF were not measured in HTF supplemented with acid-treated FCS. The reason for this is unclear and may be a result of acidification, or of a species difference.

The detection of embryo-derived PAF in media containing serum suggests that embryo-derived PAF is not susceptible to serum acetylhydrolase and may be protected in some way, perhaps by a binding protein or carrier molecule (Collier et al., 1990).

It has been shown that early stage sheep embryos produce the ether phospholipid PAF. The mean amount of PAF produced by sheep embryos $(60.9 \pm 9.8 \mathrm{pmol} / \mathrm{embryo} / 24 \mathrm{~h})$ was comparable to that reported for human (range $9-717 \mathrm{pmol} / \mathrm{embryo} / 24 \mathrm{~h}$ ) and mouse $(1 \cdot 5-31.0 \mathrm{pmol} / \mathrm{embryo} /$ $24 \mathrm{~h}$ ) embryos (Collier et al., 1988). The four culture media used in this study supported the production of PAF by some sheep embryos to a similar extent. It was shown previously that culture in vitro compromised the capacity of mouse embryos to secrete PAF (Ryan et al., 1989), but that the addition of exogenous PAF could apparently compensate for this, resulting in enhanced metabolism and viability for both human (O'Neill et al., 1989) and mouse embryos (Ryan et al., $1990 \mathrm{a}, \mathrm{b})$. This evidence, with the current demonstration of variable ovine embryo-derived PAF secretion, suggests that PAF might also be beneficial as a supplement to ovine embryo culture media.

We thank B. G. Miller, J. Ellsmore and L. Simmul for their assistance in preparation of animals and surgical procedures during this experiment. We also thank M. Jones for assistance with the statistical analysis. This work was supported by a grant from the Australian National Health and Medical Research Council (C. O’Neill). K. M. Battye is supported by an Australian postgraduate research award.

\section{References}

Ammit, A.J. \& O'Neill, C. (1991) Comparison of a radioimmunoassay and bioassay for embryo-derived platelet activating factor. Hum. Reprod. 6, 872-878.

Battye, K.M., Evans, G. \& O'Neill, C. (1989) A role for platelet activating factor in maintenance of the ovine corpus luteum. Proc. Aust. Soc. Reprod. Biol. 21, abst 32 .

Benveniste, J., LeCouedic, J.P., Polonsky, J. \& Tence, M. (1977) Structural analysis of purified platelet activating factor by lipases. Nature (Lond.) 269, 170.

Blank, M.L., Hall, M.N., Cress, E.A. \& Snyder, F. (1983) Inactivation of 1-alkyl-2-acetyl-sn-glycero-3phosphocholine by a plasma acetylhydrolase: higher activities in hypertensive rats. Biochem. biophys. Res. Commun. 113, 666671 .

Caramelo, C., Fernandez-Gallardo, S., Marin-Cao, D., Inarrea, P., Santos, J.C., Lopez-Novoa, J.M. \& Sanchez Crespo, M. (1984) Presence of platelet activating factor in blood from human and experimental animals. Its absence in anephric individuals. Biochem. biophys. Res. Commun. 120, 789-796.

Cooney, S.J., Smal, M.A., Harle, D.G. \& Baldo, B. (1990) Combining site specificities of rabbit antibodies to platelet-activating factor (PAF). Molec. Immunol. 27, 405-412.

Collier, M., O'Neill, C., Ammit, A.J. \& Saunders, D.M. (1988) Biochemical and pharmacological characteri- zation of human embryo-derived platelet activating factor. Hum. Reprod. 3, 993-998.

Collier, M., O'Neill, C., Ammit, A.J. \& Saunders, D.M. (1990) Measurement of human embryo-derived platelet-activating factor (PAF) using a quantitative bioassay of platelet aggregation. Hum. Reprod. 5, 323-328.

Gross, T.S., Thatcher, W.W., O'Neill, C. \& DanetDesnoyers, G. (1990) Platelet-activating factor alters the dynamics of prostaglandin and protein synthesis by endometrial explants from pregnant and cyclic cows at Day 17 following oestrus. Theriogenology 34, 205-218.

Handley, D.A., Tomesch, J.C. \& Saunders, R.N. (1986) Inhibition of PAF-induced systemic responses in the rat, guinea pig, dog and primate by the receptor antagonist SRI 63-441. Thromb. Haemostasis 56, 4044.

Hansel, W. (1988) Establishment of pregnancy: regulation of the corpus luteum. Proc. 11th Int. Congr. Anim. Reprod. Artificial Insem. pp. 61-68. Dublin.

Moore, N.W. (1980) Embryo transfer: procedures and results obtainable in sheep and goats. In Current Therapy in Theriogenology, pp. 89-94. Ed. D. A. Morrow. W. B. Saunders Co., Philadelphia.

O'Neill, C. (1985) Partial characterization of the embryo-derived platelet-activating factor in mice. $J$. Reprod. Fert. 73, 567-577. 
O'Neill, C. (1987) Embryo-derived platelet activating factor: a preimplantation embryo mediator of maternal recognition of pregnancy. Domestic Animal Endocr. 4, 69-85.

O'Neill, C., Ryan, J.P., Collier, M., Saunders, D.M., Ammit, A.J. \& Pike, I.L. (1989) Supplementation of in-vitro fertilisation culture medium with platelet activating factor. Lancet ii, 769-772.

Quinn, P., Warner, G.M., Kerin, J.R. \& Kirby, C. (1985) Culture factors affecting the rate of in vitro fertilization and embryo transfer. Ann. NY Acad. Sci. 442, 195-203.

Ryan, J.P., Spinks, N.R., O'Neill, C., Ammit, A.J. \& Wales, R.G. (1989) Platelet activating factor (PAF) production by mouse embryos in vitro and its effect on embryonic metabolism. J. Cell. Biochem. 40, 387-395.

Ryan, J.P., O’Neill, C. \& Wales, R.G. (1990a) Oxidative metabolism of energy substrates by preimplantation mouse embryos in the presence of platelet-activating factor. J. Reprod. Fert. 89, 301-307.

Ryan, J.P., Spinks, N.R., O'Neill, C. \& Wales, R.G. (1990b) Implantation potential and fetal viability of mouse embryos cultured in media supplemented with platelet-activating factor. J. Reprod. Fert. 89, 309-315.

Smal, M.A., Baldo, B.A. \& Redmond, J.W. (1989) Production of antibodies to platelet activating factor. Molec. Immunol. 26, 711-719.
Smal, M.A., Baldo, B.A. \& Harle, D.G. (1990) The specificity of the binding of platelet activating factor (PAF) to anti-PAF antibodies. J. molec. Recognition 3, $168-172$.

Smith, S.K. \& Kelly, R.W. (1988) Effect of plateletactivating factor on the release of PGF-2 $\alpha$ and PGE-2 by separated cells of human endometrium. $J$. Reprod. Fert. 82, 271-276.

Spinks, N.R. \& O'Neill, C. (1988) Antagonists of embryo-derived platelet-activating factor prevent implantation of mouse embryos. J. Reprod. Fert. 84, 89-98.

Spinks, N.R., Ryan, J.P. \& O'Neill, C. (1990) Antagonists of embryo-derived platelet-activating factor act by inhibiting the ability of the mouse embryo to implant. J. Reprod. Fert. 88, 241-248.

Steel, G.D. \& Torrie, J.H. (1981) Principles and Procedures of Statistics. A Biometrical Approach. McGraw-Hill International Book Co., New York.

Walker, S.K., Seamark, R.F., Quinn, P., Warnes, G.M., Ashman, R.J., Smith, D.H. \& Ancell, P. (1988) Culture of pronuclear embryos of sheep in a simple medium. Proc. 11th Int. Congr. Anim. Reprod. Artificial Insem., abst 483, Dublin.

Received 11 December 1990 